\title{
Reverse engineering the ancient ceramic technology based on X-ray fluorescence spectromicroscopy
}

\author{
Philippe Sciau, ${ }^{* a}$ Yoanna Leon, ${ }^{a}$ Philippe Goudeau, ${ }^{b}$ Sirine C. Fakra, ${ }^{c}$ Sam Webb ${ }^{d}$ and Apurva Mehta ${ }^{d}$
}

\begin{abstract}
We present results of X-ray fluorescence (XRF) microprobe analyses of ancient ceramic cross-sections aiming at deciphering the different firing protocols used for their production. Micro-focused XRF elemental mapping, Fe chemical mapping and Fe K-edge X-ray absorption near edge structure spectroscopy were performed on pre-sigillata ceramics from southern Gaul, and terra Sigillata vessels from Italy and southern Gaul. Pieces from the different workshops and regions showed significant difference in the starting clay material, clay conditioning and kiln firing condition. By contrast, sherds from the same workshop exhibited more subtle differences and possible misfirings. Understanding the precise firing conditions and protocols would allow recreation of kilns for various productions.

Furthermore, evolution and modification of kiln design would shed some light on how ancient potters devised solutions to diverse technological problems they encountered.
\end{abstract}

\section{Introduction}

The ceramic production in the Greek and Roman periods reached new heights, through the development of high-gloss surface finishes and control of color (red or black) through vitrification and redox chemistry of an iron oxide-rich clay material. ${ }^{1-6}$ From settling and decantation of the starting clay, a liquid slip was prepared. Vessels were either painted or dipped into this liquid clay slip before firing. The high-gloss black coatings were the first ceramics of this kind produced. They are the famous Attic vessels, ${ }^{1}$ first developed and perfected by the Athenians at the late $6^{\text {th }}$ century $\mathrm{BC}$, but were also produced in other parts of Greece and Greek colonies. ${ }^{7}$ The Greek pottery technology further developed to produce several types of red slips and at its pinnacle was creating iconic red and black vessels. The manufacture of the high-gloss black pottery continued in to the Roman period and in particular through the production of Campanian tableware. ${ }^{2,3}$

${ }^{a}$ CNRS, CEMES, Université de Toulouse, 29 rue J. Marvig, F-31055 Toulouse, France. E-mail: philippe.sciau@cemes.fr; Fax: +33562257999; Tel: +33562257850

${ }^{b}$ Institut Pprime, CNRS, Université de Poitiers, ENSMA, Bd Marie et Pierre Curie, F-86962 Futuroscope Chasseneuil, France. E-mail: philippe. goudeau@univ-poitiers.fr; Fax: +33 549496692; Tel: +33549496726

'ALS, Lawrence Berkeley National Lab, 1 Cyclotron Road, Berkeley, CA, 94720, USA. E-mail: sfakra@lbl.gov; Fax: +1 5104864102; Tel: +1 5104952855

${ }^{d}$ SSRL, SLAC, 2575, Sand Hill Road, Menlo Park, CA, 94025, USA. E-mail: mehta@slac.stanford.edu; Fax: +1 6509264791; Tel: +1 6509264791
The vessels with black slip were fired at high temperature and in reducing conditions to sinter the slips. On cooling, oxygen was unable to diffuse into the more vitrified slips keeping them black, whereas the more porous material re-oxidized becoming red. A key technological development in production of these vessels was the control of the macro- and nanoscale porosity, and the control of the redox atmosphere of the firing kiln. The vessels with highgloss red slips, on the other hand, were sintered under oxidizing conditions. The challenge here was to maintain a sufficiently oxidizing condition at high temperatures in a wood-fired kiln. For both color of glosses, once the slips began to vitrify, the process of re-oxidation was difficult to control, resulting in parts of slips intended to be black accidentally turning red, and red slips coming out of the kiln non-uniform in shade. The fully oxidized slips were brick red whereas the less oxidized were dull brown or even grey. The Romans overcame these difficulties by improved kiln designs that enabled production of Terra Sigillata, a fine Roman tableware ceramic generated in industrial quantity by a few large workshops. In these new kilns the vessels were isolated from the flames and the products of wood combustion, such as smoke, soot and other unburned hydrocarbons, ${ }^{4,8,9}$ lead to the fabrication of thousands of vessels with high gloss and very homogeneous red color. ${ }^{10}$

The practitioners of this complex and evolving technology must have paid a lot of attention to the nature of the starting clay, and the master potters must have understood intricacies of firing Fe-rich clay sufficiently well to develop the kilns through the different stages as the pottery evolved. Unfortunately, however, very few kilns from this period have been discovered during the excavations of pottery workshops and even when a few were discovered not much of it was found besides the base. 
Over the past decade several state of the art characterization techniques, such as synchrotron based micro-focused beam X-ray Fluorescence ( $\mu \mathrm{XRF}$ ) and X-ray Absorption Near Edge Structure ( $\mu$ XANES) spectroscopy have been used to study archeological and cultural heritage material. Here, we have applied these techniques to study the local mineralogy and map the Fe valence state, to better understand the firing technology used to produce these remarkable vessels. In that respect we are following in the foot-steps of previous pioneers, such as Manolis Pantos and his group at Daresbury (UK) who have investigated Greek, Roman and Etruria ceramics using synchrotron based techniques and showed for instance that the magnetite/hercynite ratio varies greatly between different productions. ${ }^{11,12}$ Unfortunately, however, in their studies, the size of beam was greater than $50 \mu \mathrm{m}$, whereas the slip layers on most of these vessels are between 20 and $40 \mu \mathrm{m}$ thick, making it impossible to map precisely the spatial distribution of iron oxides and other associated mineral phases in the slip. The distribution of Fe minerals in the slips provides important clues into the technology used to make sophisticated ceramic that are still challenging to replicate to these days. Furthermore probing the firing protocol, kiln atmosphere and slip composition are key features for assessing the production quality of the potteries.

Here, we performed synchrotron based micro-focused X-ray Fluorescence $(\mu \mathrm{XRF})$ and X-ray Absorption Near Edge Structure ( $\mu$ XANES) spectroscopy on pottery specimen cross-sections previously prepared for scanning electron microscopy (SEM) or electron microprobe analyses. We used a micro-X-ray beam to map the mineralogy of the ceramic samples and show that the essential aspect of the firing protocol can be traced back from the nature and the spatial distribution of iron oxides in the slip and the body. Moreover, we performed in depth iron valence distribution mapping to gain information on the redox conditions and the temperatures undergone by the ceramics, crucial for reverse engineering the technology.

To further our understanding of the evolution of the ceramic technology of this period, we studied vessels produced by different technologies, but from the same workshop, La Graufesenque (Millau, France), the leading Gallic workshop of the first century AD. ${ }^{13-15}$ Before starting the production of high quality sigillata, La Graufesenque generated ceramics that imitated the Italian sigillata forms (more often called pre-sigillata). ${ }^{16}$ The slip, like the Italian and earlier Attica ware, was made by the application of a fine-textured clay applied to a coarsertextured clay body. From the color (black and/or red) and aspect (mainly non-vitrified) of the pre-sigillata tableware it is evident that these vessels were not fired in the special, highly oxidizing kilns used for the sigillata production but in traditional kilns where ceramics were in contact with flames. Thus, the atmosphere during the heating phase was often reducing and the degree of reduction depended on the presence and amount of smoke in the heating phase. There was a little more control of the atmosphere in the kiln during the cooling step, through control of ventilation. Depending on sufficiently more reducing (or oxidizing) redox conditions on cooling, black (or red respectively) body and slip resulted. ${ }^{17}$ Potters were attempting to reach a high enough temperature during the heating phase, and in some cases achieved it, to vitrify the slip and produce impermeable glossy black coating, and if the cooling was sufficiently oxidizing brown or red body. Initially these vessels were considered a consequence of a research phase in which the Gallic potters tried to re-invent the black-gloss ceramic process, but lately many consider these vessels as a specific type of pottery produced for the market. Therefore, different terms are used to classify these vessels based on whether one wants to emphasize either their relationship with Italian sigillata (imitations) or their chronology and refer to them as pre-sigillata or proto-sigillata.

The goal of this paper is to show how we can get more precise information on the firing protocol used in the pre-sigillata productions through a comparative investigation between presigillata, Italian and Gallic sigillata previously studied by X-ray diffraction (XRD), Raman spectroscopy and electron microscopy. ${ }^{18-21}$ For this purpose, we selected different sherds in the three groups: two Italian terra sigillata from Arezzo (Italy), two Gallic terra sigillata from La Graufesenque (France) and five presigillata from La Graufesenque and Bram (France). Archaeological details are given in Table 1 . Table 2 reports the global elemental composition of the slip of individual sherds and the average value for each group. The elemental and mineral compositions of each type of terra sigillata slip-Italian and Gallic-form two distinctive homogenous groups. ${ }^{19,21,22}$ The main phases in the Gallic slips are corundum, hematite and quartz while in the Italian slips, spinel, hematite and quartz were found. ${ }^{18,23}$ By contrast, the pre-sigillata slips do not constitute a homogeneous group and the elemental and mineral compositions vary greatly from one sample to another. ${ }^{19}$

\section{Experimental details}

X-Ray microprobe measurements were directly performed on the polished cross-sections made for previous electron microprobe analyses. The sherds were cut with a diamond saw and the resulting sections were mounted in epoxy and mechanically polished as shown in Fig. 1.

Micro-XRF and $\mu$ XANES measurements were performed on Beamline 2.3 of the Stanford Synchrotron Radiation Lightsource (Stanford, USA) and on Beamline 10.3.2 of the Advanced Light Source (Lawrence Berkeley National Lab, USA). ${ }^{24}$

Coarse $\mu \mathrm{XRF}$ elemental maps were first acquired at $10 \mathrm{keV}$ with a seven-element Ge solid-state detector (Canberra) using a pixel size of $20 \mu \mathrm{m} \times 20 \mu \mathrm{m}$ and a counting time of $50 \mathrm{~ms}$ per pixel to locate areas of interest. Fluorescence emission counts were collected for $\mathrm{Fe}, \mathrm{K}, \mathrm{Ca}$, and $\mathrm{Ti}$, and several other elements. High resolution $\mathrm{Fe}$ chemical maps were then acquired on these areas at several incident energies 7100 (pre-edge background), 7122,7134 and $7138 \mathrm{eV}$ with a beam size of $2.5 \mu \mathrm{m} \times 2 \mu \mathrm{m}$ (on the sample), pixel size of $2 \mu \mathrm{m} \times 2 \mu \mathrm{m}$ and a counting time of $50 \mathrm{~ms}$ per pixel. The middle two energies, 7122 and $7134 \mathrm{eV}$, were selected to give the highest positive and negative contrast between $\mathrm{Fe}^{2+}$ (e.g., hercynite) and $\mathrm{Fe}^{3+}$ (e.g., hematite) respectively. The fluorescence yield difference between $\mathrm{Fe}^{2+}$ and $\mathrm{Fe}^{3+}$ is not large at 7100 and $7138 \mathrm{eV}$ and therefore those two energies were selected to normalize the difference in the fluorescence signal due to differences in Fe concentration. The individual energy maps were normalized, deadtime corrected and registered to each other to correct for small spatial drifts. Amount of $\mathrm{Fe}^{2+}$ and $\mathrm{Fe}^{3+}$ at every pixel was estimated from the least square fit of the fluorescence yields at the four energies to background and 
Table 1 Sample description

\begin{tabular}{|c|c|c|c|c|}
\hline Reference & & Dating and/or type & Slip colour & Body colour \\
\hline \multirow{3}{*}{$\begin{array}{l}\text { Pre-sigillata from La Graufesenque } \\
\text { (Aveyron, France) }\end{array}$} & PTSGD17A & 10BC-10AD (Drag. 17) & Red non-vitrified & Red \\
\hline & PTSGD17C & 10BC-10AD (Drag. 17) & Black vitrified & Red/brown \\
\hline & PTSGD29A & 10BC-10AD (Drag. 29) & Black vitrified & Gray \\
\hline $\begin{array}{l}\text { Pre-sigillata from Bram (Aude, } \\
\text { France) }\end{array}$ & PTSB36US02B & $30 \mathrm{BC}-0$ (undetermined form) & Red non-vitrified & Red \\
\hline Sigillata from La Graufesenque & TSGFrD17B & 15AD-30AD (Drag. 17) & Red vitrified & Red \\
\hline & TSARC & & Red vitrified & Red \\
\hline
\end{tabular}

hercynite $\left(\mathrm{Fe}^{2+}\right)$ and hematite $\left(\mathrm{Fe}^{3+}\right)$ references. The $\mathrm{Fe}^{2+}$ and $\mathrm{Fe}^{3+}$ maps were subsequently assembled into a composite bicolor coded map.

Based on $\mathrm{Fe}^{2+}$ and $\mathrm{Fe}^{3+}$ valence state maps, several spots of interest were selected for Fe K-edge $\mu$ XANES analyses. Energy calibration was performed using an Fe metal foil, at Fe K-edge set to $7110.75 \mathrm{eV} .{ }^{25}$ All $\mu$ XANES spectra were collected in fluorescence mode, calibrated, deadtime corrected, pre-edge background subtracted and post-edge normalized using standard procedures. ${ }^{26}$ The spectra performed at SSRL were collected from 7100 to $7300 \mathrm{eV}$ whereas the spectra collected at the ALS for the least square linear combination fitting (LCF) were performed in the 7010-7410 eV range. The fine structure of the spectrum in the first $100 \mathrm{eV}$ after the edge (XANES) is due to the electronic structure of the sample (Fe-p partial density of unoccupied states). The fine structure in this energy range is sensitive to the chemical bonds in the surroundings of the excited atom. Above $100 \mathrm{eV}$ after the edge (EXAFS), the signal is sensitive to the atomic order and to the PDF. LCF was conducted using the ALS public library of well-characterized standards containing 54 minerals from 24 groups (metal, sulfide, carbide, olivine, orthopyroxene, clinopyroxene, silicate glass, phyllosilicate, amphibole, sulfate, carbonate, and others). ${ }^{27}$ Mineral identification using this method is generally not unique, but mineral group identification has proven to be robust with many minerals within a given group displaying similar XANES spectra. ${ }^{28}$ The best linear combination fit was obtained by minimizing the normalized sumsquares residuals [NSS $=100 \times \Sigma\left(\mu_{\exp }-\mu_{\text {fit }}\right)^{2} / \Sigma\left(\mu_{\exp }\right)^{2}$, where $\mu$ is the normalized absorbance. The error on the estimated percentages of species present using this procedure is estimated to be $\pm 10 \%$. Normalization and least square fit of the SSRL data for generation of composite XRF maps were performed with the software package SMAK (Sam's microprobe analysis kit). All ALS beamline 10.3.2 data processing, including Fe XANES LCF fitting, were carried out using a suite of custom LabView based programs available at the beamline.

\section{Results and discussion}

\section{Pre-sigillata}

Five pre-sigillata produced at La Graufesenque and Bram workshops (Table 1) falling into four distinct classes, based on the vitrification and the color of the slip and the body, were investigated:

(1) a black vitrified slip with a black body (PTSGD29A),

(2) two black vitrified slips with a brown-red body (PTSGD17C and PSTGD17H),

(3) a non-vitrified red and black slip with a red body (PTSGD17A) and

(4) a non-vitrified red slip with a red body (PTSB36US02B).

Fig. 2 shows the elemental distribution maps for two of the pre-sigillata cross-sections. The slips contain more iron and potassium and less calcium, these and the other elemental distributions are in agreement with previous electron microprobe measurements (Table 2) and the elemental maps obtained by EDS in a scanning electron microscope. ${ }^{21}$ The body, unlike the slip, is very heterogeneous and appears to contain several large crystallites, again consistent with SEM and optical observations. Many of the large crystals $(\geq 5 \mu \mathrm{m})$ in the body are quartz, pyroxene, anorthite or other feldspars, while these minerals were rarely found in the slips, supporting the hypothesis of size fractionation of the slip via sedimentation of the starting clay.

Elemental distribution maps of ceramics from Bram and La Graufesenque exhibit clear differences. $\mathrm{Ca}$ is mostly found as large crystallites in the Bram body (left column in Fig. 2), whereas it is more homogeneously distributed in the La Graufesenque sample (right column in Fig. 2). There are also significant differences in the $\mathrm{Fe}$ and $\mathrm{K}$ distributions: in the Bram ceramic $\mathrm{Fe}$ is mostly localized in the slip while the difference between the slip and the body is less high for La Graufesenque ceramics. By contrast the potassium distribution appears to be the opposite. Elemental distribution maps of the four other samples from La Graufesenque are very similar to the ones shown in Fig. 2. The differences in the elemental distribution in the large crystallite and of the average composition of the slip and the body suggest that the starting clay and probably the process of forming the slurry for the slip were distinctly different in these two pre-sigillata productions.

The $\mathrm{Fe}$ valence state maps for the pre-sigillata samples are shown in Fig. 3. As expected, the color of the ceramic is highly correlated to the $\mathrm{Fe}^{2+}$ and $\mathrm{Fe}^{3+}$ distributions: the higher the $\mathrm{Fe}^{2+}$ concentration the deeper the black and the higher the $\mathrm{Fe}^{3+}$ concentration the brighter the reds, with mixed $\mathrm{Fe}$ valence corresponding to shades of brown. The $\mathrm{Fe}^{2+}$ and $\mathrm{Fe}^{3+}$ distributions also strongly correlate with the firing conditions and history, and as Fig. 3 indicates lead to significant variation 


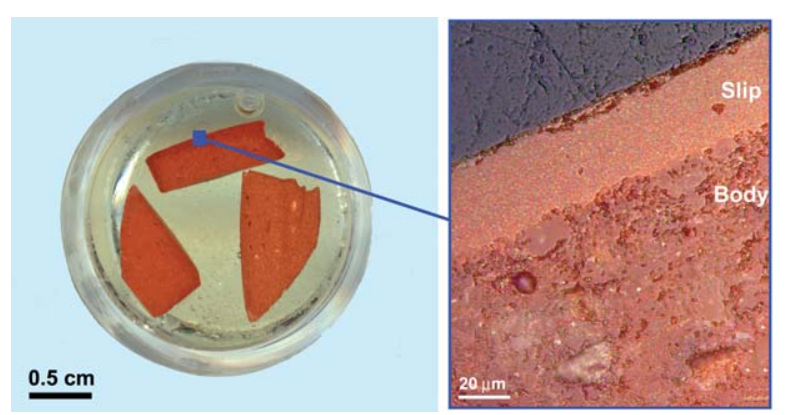

Fig. 1 Example of a cross-section sample mounted in epoxy support.

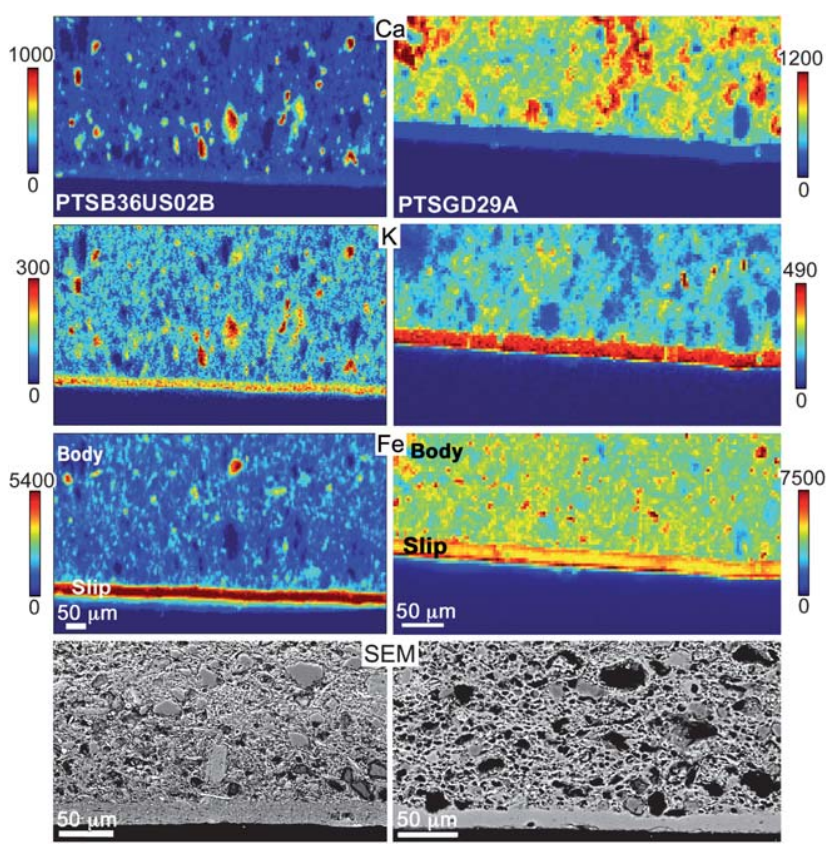

Fig. 2 Micro-XRF elemental maps (top) and SEM images (bottom) for the PTSB36US02B (left) and PTSGD29A (right) pre-sigillata (recorded at SSRL, scale in count number).
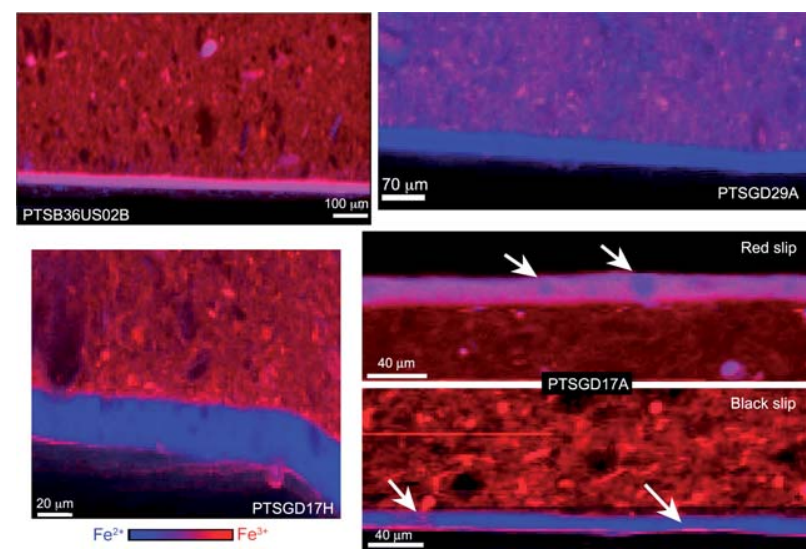

Fig. 3 Bicolor coded Fe valence state maps for the pre-sigillata recorded at $\operatorname{SSRL}\left(100 \% \mathrm{Fe}^{2+}\right.$ in blue and $100 \% \mathrm{Fe}^{3+}$ in red). Arrows point the major $\mathrm{Fe}^{2+}$ inclusions in $\mathrm{Fe}^{3+}$ and inversely. 
among the four classes of pre-sigillata investigated. The $\mathrm{Fe}$ valence state maps were supplemented by XANES spectra (see Fig. 4 and 5) and $\mu$ XRD patterns in regions of the slip and body.

Based on $\mathrm{Fe}^{2+}$ and $\mathrm{Fe}^{3+}$ distribution maps and XANES results, the sherd from Bram (PTSB36US02B) appears to have the simplest firing history. Both the slip and the body of this ceramic sherd are mostly $\mathrm{Fe}^{3+}$-rich. Furthermore, XANES spectra of both slip and body are very similar to hematite, indicating that the final firing step was highly oxidizing and either the ceramic never saw a reducing atmosphere keeping the slip red, or more likely that the sherd did not reach a high enough temperature for the slip to vitrify sufficiently, as evidenced in the SEM micrograph (Fig. 2), to seal it against subsequent oxidation.

The slips of the pre-sigillata from La Graufesenque, though significantly different from each other, are all denser than the bodies. $\mu$ XANES spectra indicate they all contain at least some hercynite and therefore are more reduced than the Bram sherd slips. These results suggest that the La Graufesenque ceramics had slips either composed of lower melting minerals or subjected to higher temperatures and vitrification occurred under sufficiently reducing conditions. The body of all of the La Graufesenque ceramic samples shows the presence of hematite (and on average higher Fe oxidation than the slip) suggesting that they were cooled under at least partially oxidizing conditions and the unvitrified body porous permeable to oxygen allowed Fe phases to oxidize to hematite. In spite of these similarities PTSGD29A shows significant difference from the other La Graufesenque pieces. The grey colored body of this ceramic shows that $\mathrm{Fe}$ phases are a mixture of hematite and hercynite and the concentration of hematite (and hence $\mathrm{Fe}^{3+}$ ) is significantly less than in the other (red or brown) bodies. Also, the slip on this ceramic is almost pure hercynite, whereas the others show some $\mathrm{Fe}^{3+}$ in the form of hematite and magnetite especially as a surface oxidation layer. This indicates that the final cooling step for PTSGD29A even though at least partially oxidizing was significantly shorter or less oxidizing than the others.

The PTSGD17A sample, with the red and black slips, is a rather interesting case. The $\mathrm{Fe}^{2+}$ and $\mathrm{Fe}^{3+}$ distributions in the black slip side are similar to those of PTSGD17H and the red slip side shows the characteristics of the PTSB36US02B sample. However, the amount of hematite (and $\mathrm{Fe}^{3+}$ ) in the black slip and the amount of hercynite $\left(\mathrm{Fe}^{2+}\right)$ in the red slip are higher than in other black and red slips, respectively.

Although the average elemental compositions of the two slips are close, SEM observations show that the black slip is slightly less porous than the red slip. Thus, the red slip was more oxidized than the black slip during the cooling phase. The difference in microstructure between the two slips could be due to the small variation in the Ca content as proposed for the Attic slips. ${ }^{29}$ In addition, SEM observations show that the grain size is larger in the red slip. Both the $\mathrm{Ca}$ ratio and the larger grain size are consistent with the larger porosity.

\section{Terra sigillata}

Four terra sigillata samples were investigated: two from the La Graufesenque workshop and two from the Arezzo workshop (Table 1). Fig. 6 shows elemental maps obtained on one crosssection from each workshop. Elemental distributions are in

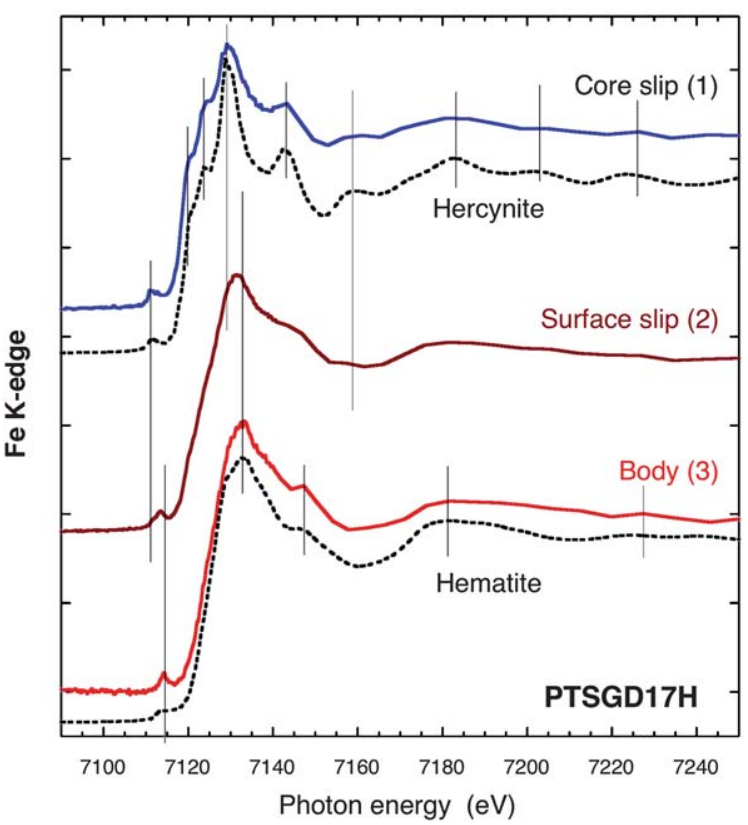

Fig. 4 Fe K-edge $\mu$ XANES spectra (recorded at SSRL) of the top surface (2), slip core (1) and body (3) of PSGD17H pre-sigillata compared to the hematite and hercynite reference spectra from the ALS Fe XAS database. ${ }^{24}$

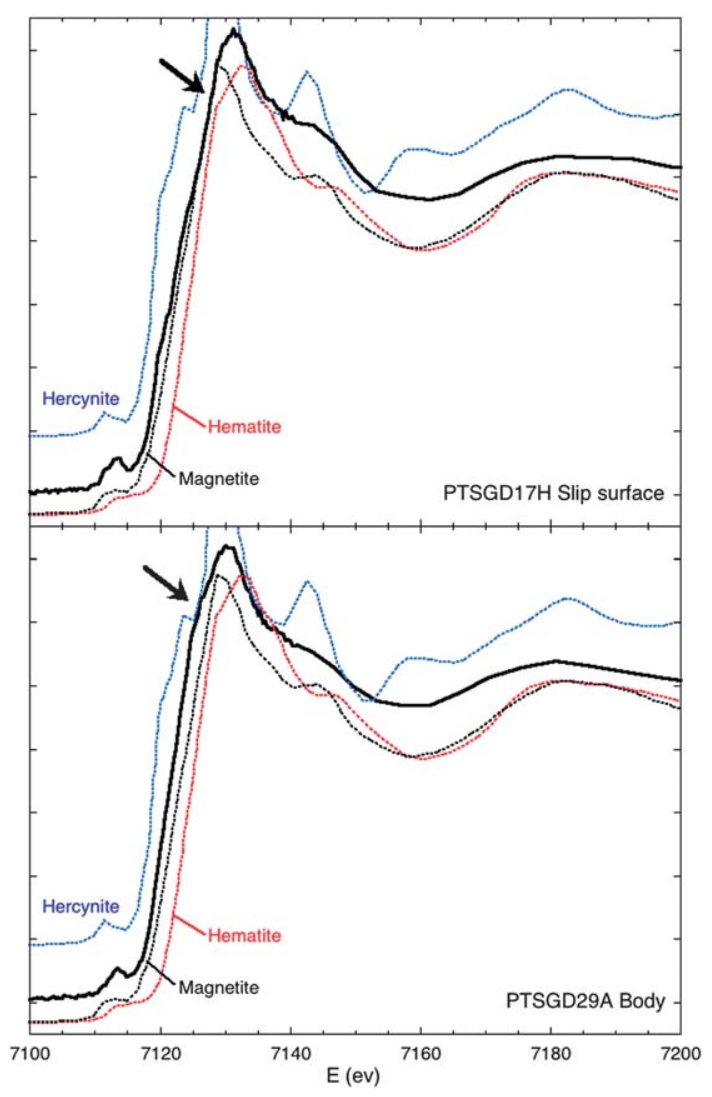

Fig. 5 Fe K-edge $\mu$ XANES spectra (recorded at SSRL) of PTSGD29A and PTSGD17H samples compared to the hematite, hercynite and magnetite reference spectra from the ALS Fe XAS database. ${ }^{24}$ 


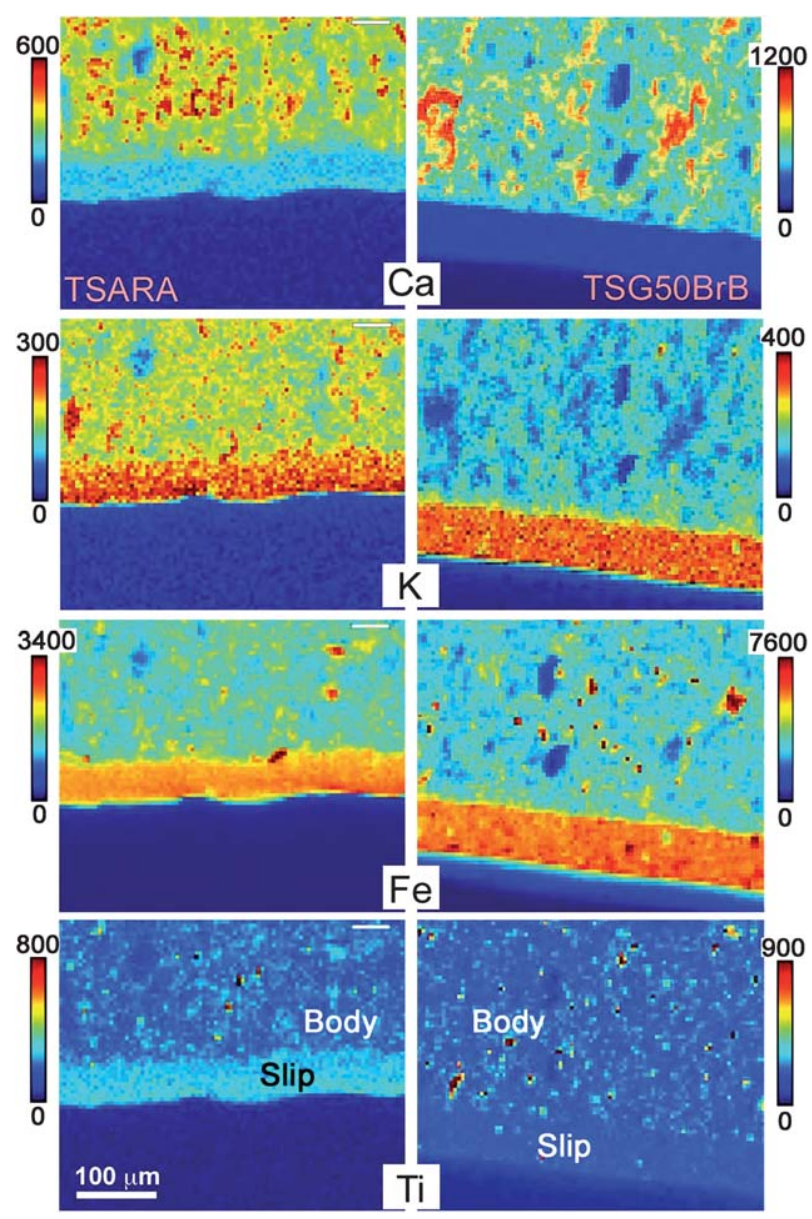

Fig. 6 Micro-XRF elemental maps for an Italic (left) and a Gallic (right) sigillata (recorded at SSRL, scale in count number).

agreement with the difference in the composition of slip and body previously measured by electron microprobe, summarized in Table 2. The slips contain more Fe and K, and less Ca than the body, however, the contrast is less marked for the Italian terra sigillata, and is in agreement with the global elemental compositions. The Italian slip appears more homogeneous than the Gallic one while the opposite is observed for the body. The other terra sigillata samples gave similar results.

Concerning the Fe redox state, all samples are predominantly $\mathrm{Fe}^{3+}$ rich (Fig. 7 and 8 ). But a small amount of $\mathrm{Fe}^{2+}$ is still found, mostly in the core of slips or in some rather well vitrified area of the body. The presence of $\mathrm{Fe}^{2+}$ in the core of slips is a consequence of the small amount of accidental reduction during the heating step. The difference in the Fe valence state distribution obtained for the various terra sigillata vary significantly. There is a negligible amount of $\mathrm{Fe}^{2+}$ in the later sigillata from La Graufesenque (TSG50BrB), whereas the earlier non-vitrified protosigillata (PTSB36US02B) shows significant signs of reduction and therefore reflects the efficiency of the different sigillata kilns to maintain oxidizing conditions during the whole thermal process.

The various $\mathrm{Fe}$ XANES spots chosen in the slip and the ceramic body showed spectra similar to each other and close to the reference spectrum of hematite. But, in order to determine possible small differences between the slips, LCF fitting of the
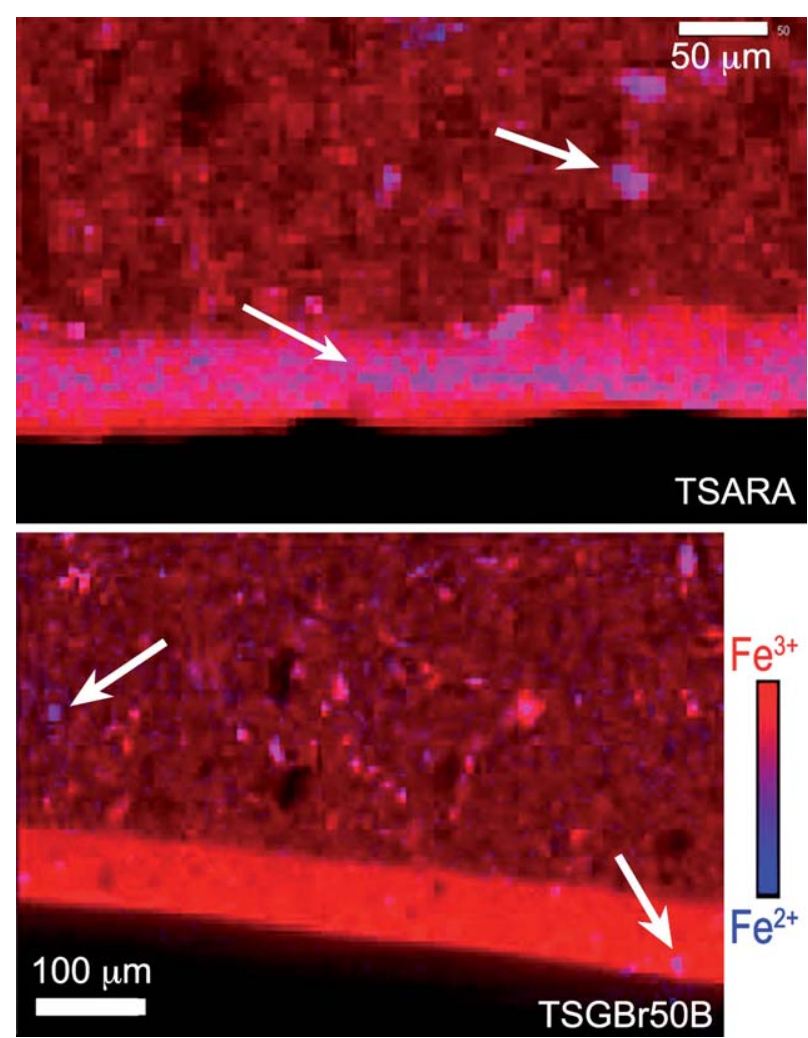

Fig. 7 Bicolor coded Fe valence state maps of sigillata recorded at the $\operatorname{SSRL}\left(100 \% \mathrm{Fe}^{2+}\right.$ in blue and $100 \% \mathrm{Fe}^{3+}$ in red). Arrows point the major $\mathrm{Fe}^{2+}$ inclusions in $\mathrm{Fe}^{3+}$

XANES spectra using an Fe XAS spectral database of well characterized standards ${ }^{27}$ was performed. The best fits were obtained with a linear combination of three phases: smectite clay, hematite and maghemite or hematite, smectite clay and osumilites $^{30}$ for the Italian and Gallic samples respectively (Table 3). The amount of hematite is higher in the Gallic slips, whereas Fe in the Italian slips appears to be not that different from the smectite reference spectrum (Fig. 9). Though the differences between the Italian and Gallic production are not large, they seem to be significant. These differences in the mineralogy of the

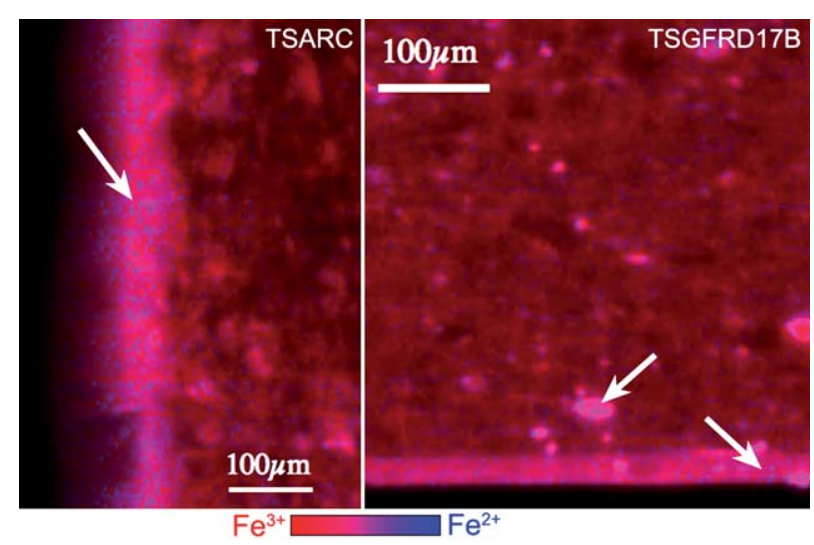

Fig. 8 Bicolor coded Fe valence state maps of sigillata recorded at ALS $\left(100 \% \mathrm{Fe}^{2+}\right.$ in blue and $100 \% \mathrm{Fe}^{3+}$ in red). Arrows point the major $\mathrm{Fe}^{2+}$ inclusions in $\mathrm{Fe}^{3+}$. 
Table 3 LCF fitting results of some sigillata Fe K-edge $\mu$ XANES spectra recorded at the ALS

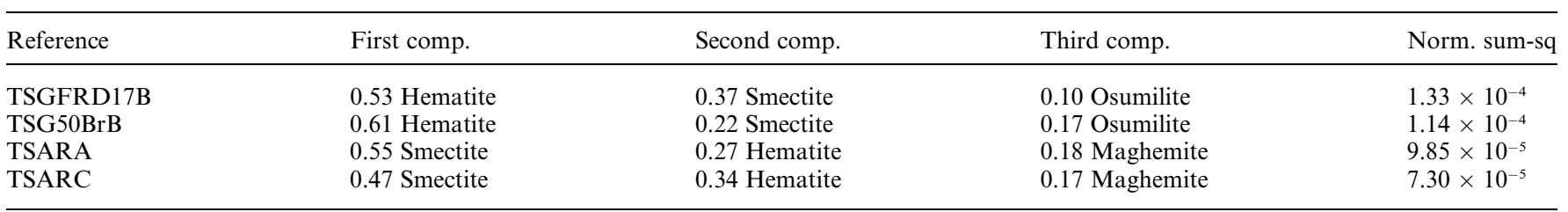
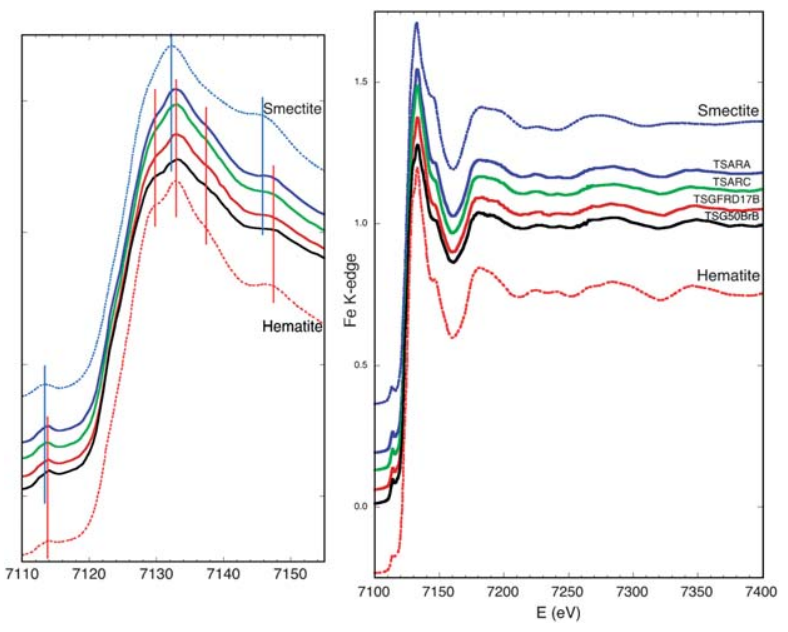

Fig. 9 Fe K-edge $\mu$ XANES spectra (recorded at ALS) characteristic of the 4 sigillata slips studied and compared to the hematite and smectite reference spectra from the ALS Fe XAS database. ${ }^{24}$

fired slip appear to come from the differences in the minority phase mineralogy of the starting clay. ${ }^{22,23}$ Hematite and quartz are the primary components of the slip for both the productions, Italian slips contain a spinel phase while Gallic slips contain corundum. However, none of these minority components (i.e., smectite, maghemite or osumilites) were detected by X-ray diffraction. ${ }^{18,21,23,31}$ Previous electron energy loss spectroscopy (EELS) studies indicate that the corundum of Gallic slips contains around $8 \%$ of iron $^{18}$ and recent investigations have revealed that the spinel crystals of Italian slips also contain a small amount of iron. ${ }^{21}$ X-Ray diffraction (XRD) measurements are not sensitive to Fe valency, and as maghemite and spinel are iso-structural, XRD could easily misidentify $\mathrm{Fe}^{2+}$ containing maghemite with $\mathrm{Fe}^{3+}$ containing spinel. Moreover, at the firing temperature of sigillata the clays (illite, smectite, kaolinite,... ) begin to melt destroying the long range periodicity of the minerals making XRD identification impossible, but in some cases the vitrified minerals still keep the local structural order and as XANES measurements are very sensitive to the local structural order, XAS measurements can still identify minerals present prior to vitrification. Even in the case of complete vitrification, XAS identifies the local coordination environment around the $\mathrm{Fe}$ ion in the glassy matrix. In a similar way, without containing crystal of osumilite group, some iron atoms of the matrix could have a local equivalent environment to the one of $\mathrm{Fe}$ in the osumilite structure. In addition, the majority of crystals present in the slip are much smaller than the analyzed volume and are also Fe-substituted (spinel, corundum) or $\mathrm{Al}$ and Ti-substituted (hematite). In these conditions, the recorded spectra are the addition of all the individual responses and as the spectra of these substituted crystals are not in the Fe XAS database, the fit results must be considered with caution. However, the differences between the two types of production seem significant and in relation with the difference in mineral composition, as revealed by XRD and Raman spectroscopy performed on a substantial corpus. ${ }^{20,21}$

The ability of XANES measurements to yield information on Fe valency and local structure even when the clay has completely vitrified into a glassy matrix, provides a very good complement to our previous X-ray diffraction ${ }^{23}$ and Raman spectroscopy ${ }^{20}$ investigations and as shown above provides valuable clues to distinguish between the Italian and Gallic terra sigillata productions, where other long range order dependent and valence insensitive techniques fail.

\section{Conclusions}

X-Ray fluorescence microprobe applied to cross-sections of ancient pottery sherds is a powerful tool for deciphering the different protocols used in their production. We showed that among pieces from different workshops and region pre-sigillata potteries from southern Gaul, and terra sigillata potteries from Italy and southern Gaul, significant differences in the starting clay material, clay conditioning and kiln firing were found. Sherds from the same workshop show more subtle differences and possible misfirings. Applied to a significant corpus, this approach would allow not only an estimation of the efficiency of sigillata kiln of various workshops but also show the degree of control and proficiency of a complex technology these artisans possessed. Furthermore, understanding the precise firing conditions and protocols would allow recreation of kilns for various productions. The evolution and modification of kiln design would shed some light on how ancient potters devised solutions to various technological problems they encountered.

The approach outlined here would be also invaluable to study the productions of Campanian and Attic pottery workshops and further the understanding of clay chemistry and mastery of the kiln technology these potters possessed.

\section{Acknowledgements}

The authors gratefully acknowledge Silvia Vilucchi (Arezzo museum), Alain Vernhet (TRACES, Toulouse University) and Michel Passelac (Archéologie des Sociétés miditerranéennes, Lattes-Montpellier University) for the archeological samples as well as Philippe de Parseval (GET/LMTG, Toulouse University) for the elemental composition measurements. This work was supported by the Conseil Régional de Midi-Pyrénées under contract no. 08005556-2, a France-Stanford Center grant for the 2006-2007 academic years and the Director, Office of Science, 
Office of Basic Energy Sciences, of the U.S. Department of Energy who is operating ALS and SSRL under contracts no. DEAC02-05CH11231 and DE-AC02-76-SFO0515, respectively.

\section{References}

1 J. V. Noble, The Techniques of Painted Attic Pottery, New York, 1965 2 M. Maggetti, G. Galetti, H. Schwander, M. Picon and R. Wessicken, Archaeometry, 1981, 23, 199-207.

3 M. Vendrell-Saz, T. Pradell, J. Molera and S. Aliaga, Archaeometry, 1991, 33, 109-117.

4 M. S. Tite, Archaeometry, 2008, 50, 216-231.

5 P. Mirti, X-Ray Spectrom., 2000, 29, 63-72.

6 M. S. Tite, M. Bimson and I. C. Freestone, Archaeometry, 1982, 24, $117-126$.

7 Y. Maniatis, E. Aloupi and A. D. Stalios, Archaeometry, 1993, 35, 23 34.

8 A. Vernhet, Gallia, 1981, 39, 25-43.

9 M. Picon and A. Vernhet, SFECAG, actes du Congrès de L'EscalaEmpuries, 2008, pp. 553-566.

10 M. M. Fernández and J. Buxeda i Garrigós, in 5th European Meeting on Ancient Ceramics, ed. V. Kilikoglou, A. Hein and Y. Maniatis, Archaeopress, Athens, 1999, pp. 287-297.

11 E. Gliozzo, I. W. Kirkman, E. Pantos and I. Memmi Turbanti, Archaeometry, 2004, 46, 227-246.

12 C. C. Tang, E. J. MacLean, M. A. Roberts, D. T. Clarke, E. Pantos and A. J. N. Prag, J. Archaeol. Sci., 2001, 28, 1015-1024.

13 F. Oswald and T.-D. Pryce, An Introduction to the Study of Terra Sigillata, Longmans, Green and Co., London, 1920.

14 F. Hermet, La Graufesenque, Condatomogos, Vases Sigillés, graffites, Paris, 1934.

15 M. Genin, La Graufesenque (Millau, Aveyron), Volume II; Sigillées Lisses et Autres Productions, Editions de la Fédération Aquitania, Bordeaux, 2007.

16 M. Genin, B. Hoffmann and A. Vernhet, in Céramiques de la Graufesenque et Autres Productions D'époque Romaine, Hommages à
Bettina Hoffmann, ed. M. Genin and A. Vernhet, éditions monique mergoil, Montagnac, 2002, vol. 7, pp. 45-104.

17 M. Picon, in Céramiques de la Graufesenque et Autres Productions D'époque Romaine, Hommages à Bettina Hoffmann, ed. M. Genin and A. Vernhet, éditions monique mergoil, Montagnac, 2002, vol. 7, pp. 139-163.

18 P. Sciau, S. Relaix, C. Roucau and Y. Kihn, J. Am. Ceram. Soc., 2006, 89, $1053-1058$.

19 C. Mirguet, C. Dejoie, C. Roucau, P. de Parseval, S. J. Teat and P. Sciau, Archaeometry, 2009, 51, 748-762.

20 Y. Leon, C. Lofrumento, A. Zoppi, R. Carles, E. M. Castellucci and P. Sciau, J. Raman Spectrosc., 2010, 41, 1260-1265.

21 Y. Leon, $\mathrm{PhD}$ thesis, Université de toulouse, 2010.

22 P. Sciau, C. Dejoie, S. Relaix and D. Parseval, in La Graufesenque (Millau, Aveyron); Sigillées Lisses et Autres Productions, ed. M. Genin, Editions de la Fédération Aquitania edn, Bordeaux, 2007, vol. II, pp. 23-36.

23 P. Sciau, S. Relaix, C. Mirguet, P. Goudeau, A. M. T. Bell, R. L. Jones and E. Pantos, Appl. Phys. A: Mater. Sci. Process., $2008,90,61-66$

24 M. A. Marcus, A. A. MacDowell, R. S. Celestre, A. Manceau, T. Miller, H. A. Padmore and R. E. Sublett, J. Synchrotron Radiat., 2004, 11, 239-247.

25 S. Kraft, J. Stümpel and U. Kuetgens, Rev. Sci. Instrum., 1996, 67, 681-687.

26 S. Kelly, D. Hesterberg and B. Ravel, in Methods of Soil Analysis Part 5-Mineralogical Methods, ed. A. L. Ulery and L. R. Drees, Soil Science Society of America, Madison WI. 2008, pp. 367-464.

27 M. A. Marcus, A. J. Westphal and S. C. Fakra, J. Synchrotron Radiat., 2008, 15, 463-468.

28 A. J. Westphal, S. C. Fakra, Z. Gainsforth, M. A. Marcus, R. C. Ogliore and A. L. Butterworth, Astrophys. J., 2009, 694, 18-28.

29 M. S. Walton, E. Doehne, K. Trentelman, G. Chiari, J. Maish and A. Buxbaum, Archaeometry, 2009, 51, 383-396.

30 W. A. Deer, R. A. Howie and J. Zussman, An Introduction to the Rock-Forming Minerals, Pearson, Harlow, 1992.

31 P. Sciau, P. Goudeau, N. Tamura and E. Dooryhee, Appl. Phys. A: Mater. Sci. Process., 2006, 83, 219-224. 


\section{DISCLAIMER}

This document was prepared as an account of work sponsored by the United States Government. While this document is believed to contain correct information, neither the United States Government nor any agency thereof, nor The Regents of the University of California, nor any of their employees, makes any warranty, express or implied, or assumes any legal responsibility for the accuracy, completeness, or usefulness of any information, apparatus, product, or process disclosed, or represents that its use would not infringe privately owned rights. Reference herein to any specific commercial product, process, or service by its trade name, trademark, manufacturer, or otherwise, does not necessarily constitute or imply its endorsement, recommendation, or favoring by the United States Government or any agency thereof, or The Regents of the University of California. The views and opinions of authors expressed herein do not necessarily state or reflect those of the United States Government or any agency thereof or The Regents of the University of California. Ernest Orlando Lawrence Berkeley National Laboratory is an equal opportunity employer. 